\title{
Design and Implementation of Multi Agent-based Information Fusion System for Decision Making Support (A Case Study on Military Operation)
}

\author{
${ }^{1,2}$ Arwin Datumaya Wahyudi Sumari $\&{ }^{1}$ Adang Suwandi Ahmad \\ ${ }^{1}$ Department of Electronics, Akademi Angkatan Udara, \\ Jl. Laksda Adisutjipto, Yogyakarta - 55002 \\ ${ }^{2}$ School of Electrical Engineering and Informatics, Institut Teknologi Bandung \\ Gedung Labtek VIII, Jl. Ganeca 10, Bandung - 40175
}

\begin{abstract}
Quick, accurate, and complete information is highly required for supporting strategically impact decision making in a Military Operation (MO) in order to reduce the decision cycle and to minimize the loss. For that purpose, we propose, design and implement a hierarchical Multi Agent-based Information Fusion System for Decision Making Support (MAIFS-DMS). The information fusion is implemented by applying Maximum Score of the Total Sum of Joint Probabilities (MSJP) fusion method and is done by a collection of Information Fusion Agents (IFA) that forms a multiagent system. MAIFS uses a combination of generalization of Dasarathy and Joint Director's Laboratory (JDL) process models for information fusion mechanism. Information fusion products that are displayed in graphical forms provide comprehensive information regarding the MO's area dynamics. By observing the graphics resulted from the information fusion, the commandant will have situational awareness and knowledge in order to make the most accurate strategic decision as fast as possible.
\end{abstract}

Keywords: decision making support, information fusion, MAIFS-DMS, military operation, MSJP, multiagent system.

\section{$1 \quad$ Introduction}

In a dynamic Military Operation (MO), the quality of information that is sent to the decision maker (commandant) gives a significant impact to a combat strategic plan in order to win the war and reduce the loss. A quick-and-correct decision making depends on accuracy and speed of information processing obtained from sensors that are distributed and placed strategically. In an MO, data obtained from intelligent activities such as surveillance, and reconnaissance, are processed and analyzed by the commandant's supporting staffs, which consist of intelligent, operation, personnel, logistics, and communication electronics staffs, from each one perspective. The analyzed data are then inferred and presented to the commandant as the basis for decision making. 
Information that flows continuously can cause information explosion. In addition, at this moment the process of data/information analyses in military institution such as the Indonesian Air Force is still performed conventionally so that it is not realistic to be faced with the dynamics of an MO in the information era. Another problem found in the field is that there is no single method that is applied to manage the data/information gathered from intelligent activities so as it can be used by the commandant as the basis for decision making support. Those problems affect the speed of Observe, Orient, Decide, and Act (OODA) decision cycle. In order to solve the problems, we propose, design, and implement a system that is capable to fuse or combine data from sensors and the information from the analyzed data in order to obtain comprehensive information quickly. The proposed system is called as Multi Agent-based Information Fusion System for Decision Making Support (MAIFS-DMS).

\section{Background Theories}

\subsection{Military Operation}

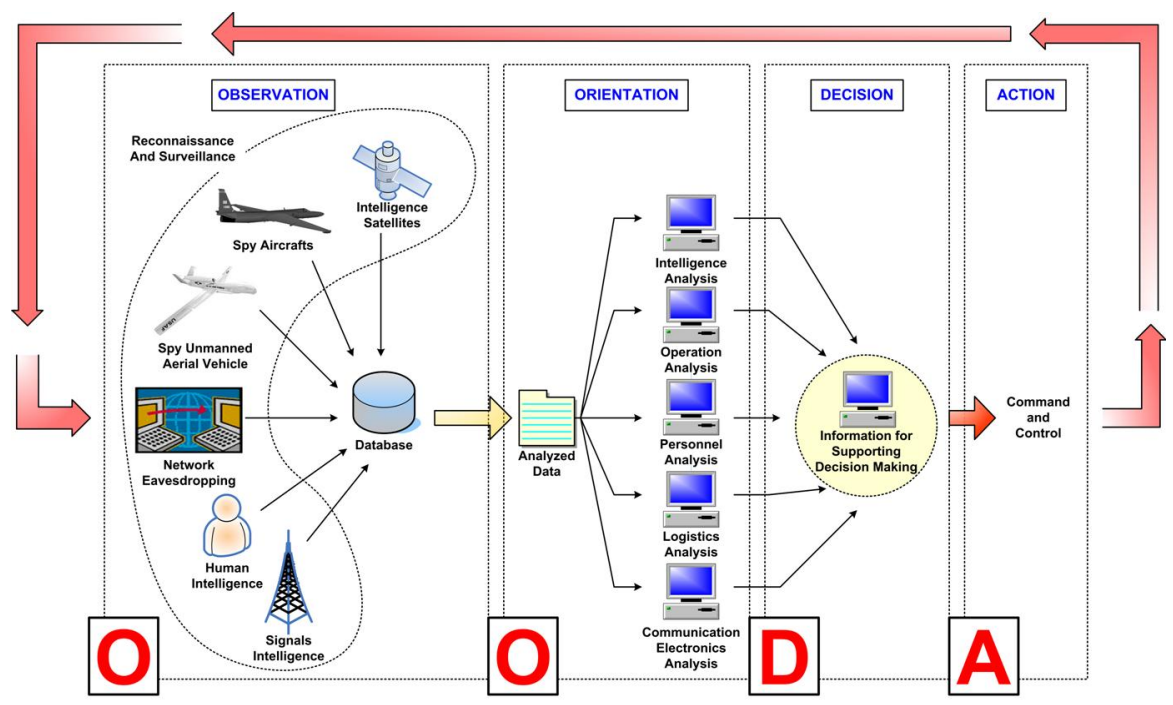

Figure 1 MO decision cycle OODA.

Military Operation (MO) is a military action or the process of carrying on combat. Basically, there are two kinds of MO, Military Operation for War (MOW) and Military Operation Other Than War (MOOTW) [1]. Whatever the type of the MO will be executed, it is always started with a planning and ended with an action. The MO planning to execution follows a repeatedly-four-phase 
military decision cycle which is called as OODA. The correct Operation Plan (OP) is always initiated by the speed of presentation of the accurate and complete information obtained from the observations of the MO area dynamics to the commandant and his supporting staffs. MO decision cycle OODA is depicted in Figure 1.

\subsection{Information Fusion}

Data or information fusion is defined as the process of combining data to refine state estimates and predictions [2]. It is also called as multi-sensor fusion which is defined as combining the readings from several sensors into a uniform data structure [3]. By its nature, the information fusion itself is an inference. So, it this paper we will use these two terms interchangeably.

Inputs to an information fusion system can be in the form of physical and nonphysical data. Non-physical data can be information gathered by means of communications with the environment or models of real-life situations, while physical data can be [4]:

- Observation data from sensors,

- Instructions and data from operator or user, or

- A priori data from an existing database

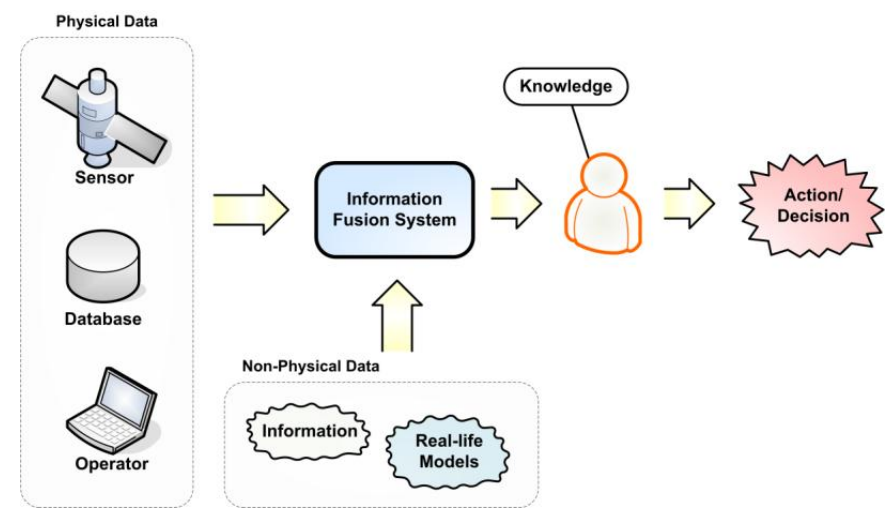

Figure 2 Illustration of the information fusion system information sources [5].

The basic idea of the information fusion mechanism is depicted in Figure 2. In this research, the inputs to the proposed information fusion system are taken from a military training intelligence database [6]. Before designing and implementing information fusion system, there are three matters that have to be understood at the first place, namely the process model, the fusion architecture as well as the fusion method related to the selected architecture, the fusion class. 


\subsubsection{Information Fusion Process Models}

There are seven process models that are commonly used for data/information fusion, as follow:

- Intelligent Cycle model, which consists of four phases, namely, data collection, collation, evaluation, and dissemination [7]

- Joint Director's Laboratory (JDL) model with its five levels, namely, level 0 for sub-object assessment, level 1 for object assessment, level 2 for situation assessment, level 3 for impact assessment, and level 4 for resource management $[2,7]$

- OODA or Boyd's control loop model, which adopts the MO decision cycle

- Waterfall model, which adopts the concept in software engineering community [7]

- Dasarathy model that defines the fusion according to types of inputs and outputs [7]

- Omnibus model, aiming to cope with the disadvantages and strengthen the advantages of the other five models previously described $[7,8]$

- Hybrid model, a combination of available process models to accommodate particular applications [9]

\subsubsection{Information Fusion Architectures}

There are three alternative architectures in information fusion applications domain with their dedicated information fusion methods as follow:

- Centralized architecture that receives raw data or feature vector as inputs

- Autonomous architecture that receives feature vector inputs or raw data and produces joint declaration outputs or estimation of the state vector. Techniques that are commonly used are voting, classical inference, Bayes theorem [10-17], Dempster-Shafer (DS) method [12,13,15], and DezertSmarandache Theory (DSmT) method [18]

- Hybrid architecture, a combination the two previous architectures

\subsubsection{Information Fusion Level Classes [7]}

Information fusion level classes are classified as follow:

- Pixel Level Fusion. This level is applied to registered pixel data from all images sets to perform detection and discrimination functions.

- Feature Level Fusion. This level combines features of objects that are detected and segmented in the individual sensor domains.

- Decision Level Fusion. Fusion in decision level combines the decisions of independent sensor detection or classification paths by Boolean operator 
(AND, OR), or by a heuristic score such as M-of-N, maximum vote [1922], or weighted sum for hard decision, and Bayes method, DS, and fuzzy variable for soft decision.

\subsubsection{Information Fusion Method}

One popular method commonly used for information fusion is Bayes inference method that is combined with maximum a posteriori (MAP) technique for selecting the best estimated inference. In our research, we found that the Bayes method with MAP technique has a limitation when facing multi-hypothesis multi-fact as will be explained in the next section.

\subsubsection{Bayes Inference Method}

Bayes formulation can produce an inference concerning an observed object viewed from existing events. If we have some hypotheses $A_{1}, A_{2}, \ldots, A_{n}$, and there exists some facts $B_{1}, B_{2}, \ldots, B_{m}$, then the a posteriori conditional probability for each object $A_{i}$ is shown in Equation (1).

$$
P\left(A_{i} \mid B_{1}, B_{2}, \ldots, B_{m}\right)=P\left(A_{i} \mid B_{j}\right)=\frac{P\left(B_{j} \mid A_{i}\right) P\left(A_{i}\right)}{P\left(B_{j}\right)}
$$

where $i=1,2, \ldots, n$ is the number of hypotheses and $j=1,2, \ldots, m$ is the number of facts.

Table 1 Illustration of Bayes inference method with MAP technique.

\begin{tabular}{ccccccc}
\hline$A_{i}$ & \multicolumn{5}{c}{ Hypotheses, $A_{i}$} \\
\hline$B_{j}$ & & $\mathbf{1}$ & $\ldots$ & $\boldsymbol{i}$ & $\ldots$ & $\boldsymbol{n}$ \\
\hline & 1 & $P\left(A_{1} \mid B_{1}\right)$ & $\ldots$ & $P\left(A_{i} \mid B_{1}\right)$ & $\ldots$ & $P\left(A_{n} \mid B_{1}\right)$ \\
& 2 & $P\left(A_{1} \mid B_{1}\right)$ & $\ldots$ & $P\left(A_{i} \mid B_{2}\right)$ & $\ldots$ & $P\left(A_{n} \mid B_{2}\right)$ \\
Facts & $\ldots$ & $\ldots$ & $\ldots$ & $\ldots$ & $\ldots$ & $\ldots$ \\
$B_{j}$ & $j$ & $P\left(A_{1} \mid B_{j}\right)$ & $\ldots$ & $P\left(A_{i} \mid B_{j}\right)$ & $\ldots$ & $P\left(A_{n} \mid B_{j}\right)$ \\
& $\ldots$ & $\ldots$ & $\ldots$ & $\ldots$ & $\ldots$ & $\ldots$ \\
& $m$ & $P\left(A_{1} \mid B_{m}\right)$ & $\ldots$ & $P\left(A_{i} \mid B_{m}\right)$ & $\ldots$ & $P\left(A_{n} \mid B_{m}\right)$ \\
\hline \multirow{2}{*}{ MAP } & & \multicolumn{5}{c}{$\max _{i=1, \ldots, j, j=1, \ldots, m}\left(P\left(A_{i} \mid B_{j}\right)\right)$} \\
\end{tabular}

One can decide the best estimated hypothesis by taking the greatest a posteriori conditional probability value, $P\left(A_{i} \mid B_{j}\right)$, a technique called as MAP decision rule. For this purpose, the a priori hypothesis must be prepared as good as 
possible. If the a priori hypothesis is not available, then "principle of indifference" must be applied by making the a priori hypothesis values equal. If in the final result exists more than one $P\left(A_{i} \mid B_{j}\right)$ with the same largest value for different hypothesis, $A_{i}$ given facts, $B_{j}$, then the MAP technique is failed to accomplish its job. Table 1 illustrates Bayes inference method with MAP technique.

\subsubsection{Maximum Score of the Total Sum of Joint Probabilities Inference Method [9]}

The Maximum Score of the Total Sum of Joint Probabilities (MSJP) inference method is the enhancement of Bayes inference method with MAP after we observe its limitation. The MSJP method is presented in Equation (2).

$$
P\left(A_{i} \mid B_{1} \& \ldots \& B_{m}\right)_{\text {estimated }}=\frac{\max _{i=1, \ldots, n}\left(\sum_{i=1}^{n} \sum_{j=1}^{m} P\left(A_{i} \mid B_{j}\right)\right)}{j}
$$

where $i=1,2, \ldots, n$ is the number of hypotheses and $j=1,2, \ldots, m$ is the number of facts.

Table 2 Illustration of the MSJP method.

\begin{tabular}{|c|c|c|c|c|c|c|}
\hline$A_{i}$ & \multicolumn{6}{|c|}{ Hypotheses, $A_{i}$} \\
\hline$B_{j}$ & & 1 & $\ldots$ & $i$ & $\ldots$ & $n$ \\
\hline \multirow{8}{*}{$\begin{array}{c}\text { Facts } \\
B_{j}\end{array}$} & 1 & $P\left(A_{1} \mid B_{1}\right)$ & $\ldots$ & $P\left(A_{i} \mid B_{1}\right)$ & $\ldots$ & $P\left(A_{n} \mid B_{1}\right)$ \\
\hline & 2 & $P\left(A_{1} \mid B_{1}\right)$ & $\ldots$ & $P\left(A_{i} \mid B_{2}\right)$ & $\ldots$ & $P\left(A_{n} \mid B_{2}\right)$ \\
\hline & $\ldots$ & & $\ldots$ & $\ldots$ & $\ldots$ & $\ldots$ \\
\hline & $j$ & $P\left(A_{1} \mid B_{j}\right)$ & $\ldots$ & $P\left(A_{i} \mid B_{j}\right)$ & $\ldots$ & $P\left(A_{n} \mid B_{j}\right)$ \\
\hline & $\ldots$ & & $\ldots$ & $\ldots$ & $\ldots$ & $\ldots$ \\
\hline & $m$ & $P\left(A_{1} \mid B_{m}\right)$ & $\ldots$ & $P\left(A_{i} \mid B_{m}\right)$ & $\ldots$ & $P\left(A_{n} \mid B_{m}\right)$ \\
\hline & & $\sum_{i=1} \sum_{j=1}^{m} P\left(A_{i} \mid B_{j}\right)$ & & $\sum_{i=i} \sum_{j=1}^{m} P\left(A_{i} \mid B_{j}\right)$ & & $\underline{\sum_{i=n} \sum_{j=1}^{m} P\left(A_{i} \mid B_{j}\right)}$ \\
\hline & & $j$ & & $j$ & & $j$ \\
\hline \multirow{2}{*}{ MSJP } & & \multicolumn{5}{|c|}{$\max _{i=1, \ldots, n}\left(\sum_{i=1}^{n} \sum_{j=1}^{m} P\left(A_{i} \mid B_{j}\right)\right)$} \\
\hline & & \multicolumn{5}{|c|}{$j$} \\
\hline
\end{tabular}

The MAP decision rule in Bayes method only takes the greatest value of a posteriori conditional probability from the available hypotheses as the best outcome. On the other hand, the MSJP method applies the total sum of joint (a posteriori conditional) probabilities from the available hypotheses and selects 
the greatest value as the best outcome. The use of $P\left(A_{i} \mid B_{1} \& \ldots \& B_{m}\right)$ notation represents fused (joint) probability of all a posteriori probability values obtained from the computation, while the word "estimated" indicates the selected fused probability is the most likely hypothesis. Table 2 illustrates the mechanism of the MSJP method.

\subsection{A Short Introduction to Agent and MultiAgent System}

Agent is defined as computer systems that have capabilities to perform autonomous actions and to interact with other agents for achieving their objectives [23]. Agent is also defined as a thing that perceives its environment via its sensors and acts on it via its effectors [24]. Basically an agent has an autonomy characteristic with some additional characteristics such as reactive, proactive, social capability and collaborative behavior, and adaptive [23,25-30].

Agent always interacts with its environment which is classified as fully observable vs. partially observable, deterministic vs. stochastic, static vs. dynamic, discrete vs. continue, episodic vs. sequential, and single agent vs. multiagent [24].

A multiagent system is a system that consists of many computing elements called agent interacting to each other by exchanging messages via computer network infrastructure [23,31]. Multiagent system is aimed to cope with more complex, more realistic, and larger-scale problems that cannot be handled by a single agent [32] and to find a solution for global problems or controlling complex systems [33].

\section{$3 \quad$ MAIFS Design [9]}

\subsection{Definitions}

\subsubsection{Generalization of the JDL Process Model}

Generalization is done at Level 0 to Level 3. We do generalization of the original JDL process model because we want the system to process certain types of input and to produce certain types of output. Accordingly, we can combine this model with the Dasarathy process model, which already divides the types of input and output for information fusion. This process model is illustrated in Figure 3.

- Level 0. Sub feature assessment, estimation, and prediction of the observed situation based on association and characterization of sub feature level data. Raw data processing is done via binary labeling association [34] 
- Level 1. Feature assessment, estimation, and prediction of entity states based on level 0 inferences

- Level 2. Situation assessment, estimation, and prediction of entity states based on the relations inferred between entities

- Level 3. Integral situation assessment, estimation, and prediction of the impacts caused by the planned or estimated or predicted actions by enemies

\subsubsection{Generalization of Dasarathy Process Model}

The original Dasarathy process model divides the types of input and output into three categories, namely data (DA), feature (FE), and decision (DE) [7]. For our system, we define two new terms, namely Inference Input (IEI) and Inference Output (IEO) to replace Decision Input (DEI) and Decision Output (DEO). Information fusion product from each level is an inference for decision making support purpose. Consequently, JDL's Level 0 is for Data Input (DAI)IEO fusion, Level 1 is for Feature Input (FEI)-IEO fusion, Level 2 is for FEIFeature Output (FEO) fusion, and Level 3 is for IEI-IEO fusion.

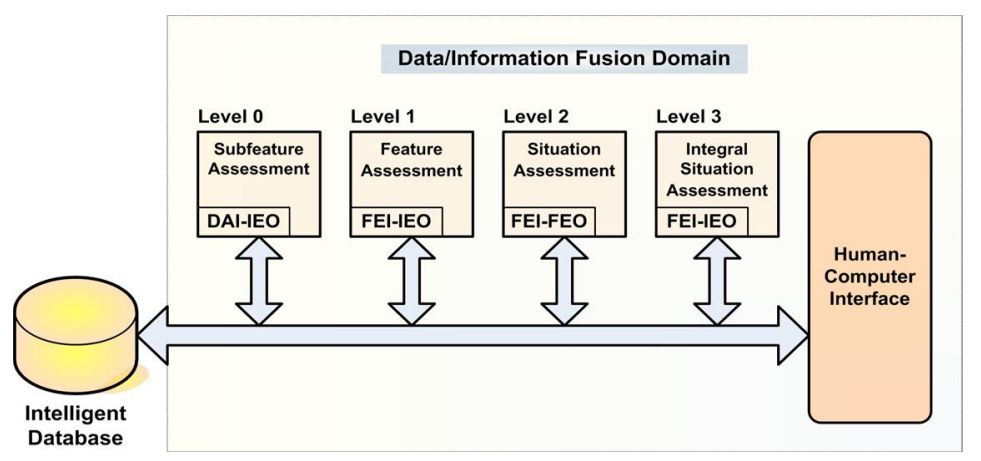

Figure 3 Generalization of Dasarathy and JDL process models [9].

\subsection{Information Fusion Agent (IFA)}

In order to automate the data/information processing, we replace the commandant's supporting staffs with agents according to each specific task. So, there will be five supporting agents, namely Intelligence Agent (IA), Operation Agent (OA), Personnel Agent (PA), Logistic Agent (LA) and Communication Electronics (Comlec) Agent (CA), and one Main Agent. All agents have information fusion capability and use the MSJP method as their information fusion or inference method.

The IFAs are distributed on each level. Agents do information fusion according to tasks and follow rules that have been assigned. As an example, the IA will 
produce an inference regarding the $\mathrm{MO}$ area situation and the $\mathrm{OA}$ only produces an inference regarding the operational aspect of the MO. The operation, personnel, logistics, and communication electronics aspects analyzing are carried out after IA finishes its task and produces inferences. At the final step, the information fusion products from all supporting agents will be delivered to the Main Agent for final information fusion process to obtain the integral situation assessment of the MO. The final product is then delivered to the commandant as the basis for decision making. The IFA configuration and the information fusion products flow is presented in Figure 4.

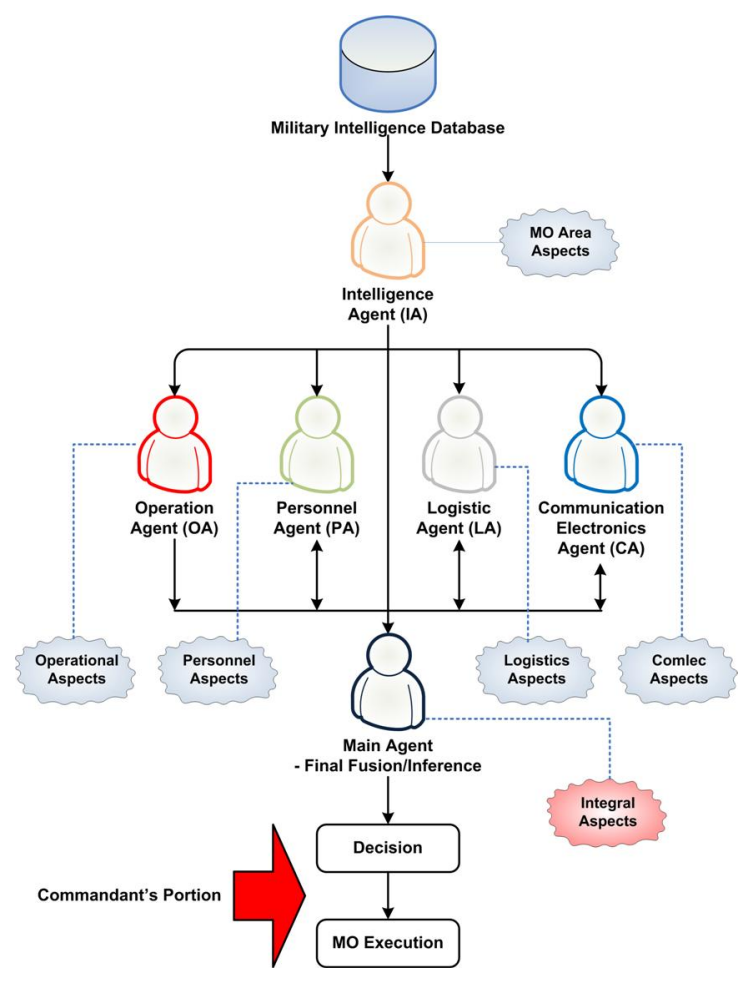

Figure 4 IFA configuration.

\subsection{MAIFS-DMS Architecture}

By referring to Section 3.1.1, the information fusion will be carried out in four levels. Level 0, Level 1, and Level 2 are used to produce the holistic view of the $\mathrm{MO}$ area that is commonly characterized by three aspects, namely weather 


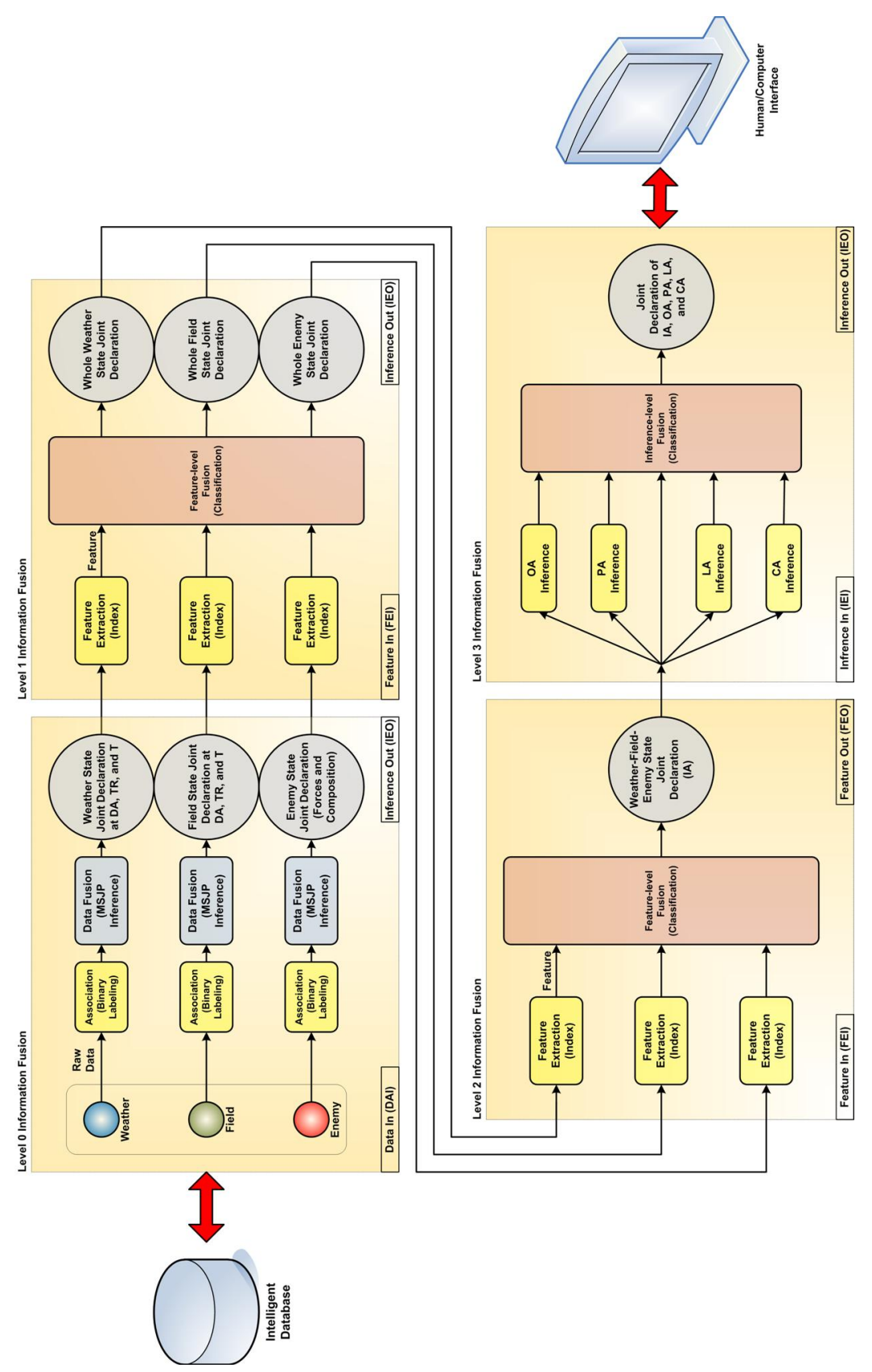

Figure 5 MAIFS-DMS architecture. 
state, field state, and enemy state. These three fusion levels will be done by the IA agent. At the last level, Level 3, other supporting agents take the IA's product and do the fusion according to their assigned task. All fusion products are then fused by the Main Agent to obtain joint declaration of IA, OA, PA, LA, and CA, which is the integral situation assessment of the MO. In order that our proposed system can work properly, we select autonomous information fusion architecture that can receive raw data and features. The complete architecture of our MAIFS-DMS is depicted in Figure 5. It shows that the types of the processed input, fusion product and fusion class are used in each level.

\subsection{Military Operation Modeling}

The important matter that must be done at the first place is to prepare inputs to the MAIFS-DMS. This can be carried out by modeling the MO. In planning an $\mathrm{MO}$, the MO domain is commonly divided into three operation areas: Departure Area (DA), Trip Route (TR), and Target area (T), and all supporting agents analyze the same MO aspects called cumemu that consist of three primary features: weather, field, and enemy [6]. Each feature consists of characteristic elements called as subfeatures and the joint (fused) declaration of these subfeatures produces information regarding the primary features states.

- Primary feature Weather state $(c u)$, commonly comprises six subfeatures: wind condition, cloud condition, rain condition, air temperature, air pressure, and visibility, which are represented by $c u_{j}$ where $j=1, \ldots, 6$. These all six elements characterize three kinds of season namely rainy season, intermediate season, and dry season, which are represented by $M_{i}$ where $i=1, \ldots, 3$ and affects the MO accomplishment.

- Primary feature Field state (me), commonly comprises four subfeatures: transportation links, forest condition, seashore condition, and mountain condition represented by $m e_{j}$ for $j=1, \ldots, 4$. These four elements characterize three types of field for the MO medium namely ground field, sea field, and air field as represented by $M d_{i}$ where $i=1, \ldots, 3$.

- Primary feature Enemy state $(m u)$, commonly comprises three subfeatures: Army units, Navy units, and Airforce units, which are represented by $M h_{i}$ with $i=1, \ldots, 3$. These three elements characterize enemy forces $(k k)$ that consists of engaged troops and reinforcing troops, and enemy composition $(k o)$ that consists of attack force, defense force, and supporting force, which are represented by $m u \_k k(k o)$ where $j=1, \ldots, 2$ for $k k$ and $j=1, \ldots, 3$ for $k o$.

\subsection{Information Fusion Mechanism Modeling}

In previous sections, we have selected the process model, the fusion architecture, the fusion class, and the fusion method. How the information 
fusion is carried out in each level and how the fusion product flows from one level to another must also be defined. For this purpose, in this section we model the information fusion mechanism in each level as well as a short explanation relating to it.

As a reminder, the information fusion at Level 0 to Level 2 is done by the IA agent. Other supporting agents (OA, PA, LA, and CA) and the Main Agent do the information fusion at the last level. The information fusion mechanism in each level conforms to the MAIFS-DMS architecture depicted in Figure 5.

\subsubsection{Level 0}

The implementation of the information fusion at Level 0 covers raw data processing of the primary features' subfeatures ситети by using MSJP method. The outcome is joint declaration of the ситети states in each operation area. The ситети information fusion is presented in Equation (3), Equation (4), and Equation (5). (See Section 3.3 for notation details).

- Subfeatures of the Weather State

$$
\text { fusi_cu_norm }[i]=\frac{\sum_{i=1}^{n} \sum_{j=1}^{m} P\left(M_{i} \mid c u_{j}\right)}{m}
$$

- Subfeatures of the Field State

$$
\text { fusi_me_norm }[i]=\frac{\sum_{i=1}^{n} \sum_{j=1}^{m} P\left(M d_{i} \mid m e_{j}\right)}{m}
$$

- Subfeatures of the Enemy State

$$
f u s i_{-} m u_{-} k k(k o)_{-} n o r m[i]=\frac{\sum_{i=1}^{n} \sum_{j=1}^{m} P\left(M h_{i} \mid m u_{-} k k(k o)_{j}\right)}{m}
$$

\subsubsection{Level 1}

The implementation of the information fusion at Level 1 is done to the information fusion products resulted at Level 0 . The outcome is joint declaration of the cumemu states in all operation areas. For subsequent information fusion at Level 2, the system selects the best estimation cumemu state that represents the cumıernu joint declaration. This mechanism is called as feature extraction. The information fusion mechanisms at this level are presented in Equation (6), Equation (7), and Equation (8).

- The Best Estimation of the Weather State 
- The Best Estimation of the Field State

$$
\text { fusi_me_all_best }=\max _{j=1, \ldots, m}\left(\sum_{j=1}^{m} \sum_{i=1}^{n} m e_{-} a l l[i][j]\right)
$$

- The Best Estimation of the Enemy State

$$
\text { fusi_mu_strongest }=\oplus\left(\begin{array}{l}
m u_{-} k k_{-} a l l_{-} \text {strongest } \\
m u_{-} o_{-} a l l_{-} \text {strongest }
\end{array}\right)
$$

\subsubsection{Level 2}

Level 2 is the last task of the IA in carrying out the information fusion. At this level, the IA fuses all information products resulted from Level 1 to obtain the joint declaration of weather-field-enemy states. The outcome resulted from this level is the IA inference describing the complete view of the MO domain. The information fusion mechanism at this level is presented in Equation (9).

$$
f u s i_{-} \text {cumemu }=\oplus\left(\begin{array}{l}
\text { fusi_cu_all_best } \\
\text { fusi_me_all_best } \\
\text { fusi_mu_strongest }
\end{array}\right)=I A
$$

\subsubsection{Level 3}

As previously explained, other supporting agents take the IA's outcome as the inputs to obtain their own inferences. But in the final information fusion, the system takes all agents' inferences to obtain the joint declaration of all MO aspects for planning and executing the MO. The inference mechanism at this level is presented in Equation (10).

$$
\text { fusi_total }=\oplus(I A, O A, P A, L A, C A)
$$

\section{MAIFS-DMS Validation [9]}

To ascertain the validity of the MSJP method in carrying out information fusion at Level 0 as depicted in Figure 5, MAIFS-DMS uses weather, field, and enemy data taken from a military training intelligence database [6] from three MO areas (i.e., DA, TR, and $\mathrm{T}$ ). In this paper, we only concentrate on the information fusion carried out in Level 0 to Level 2. Because MO is a "gonogo" operation, we have to assume the conditions or states of the features' subfeatures for subsequent processes, so they can be determined as feasible ("go") or not feasible ("nogo") subfeature in supporting the MO. Tables 3-6 list the conditions for features' subfeatures feasibility. 
Table 3 Subfeature of the Weather State Feasibility.

\begin{tabular}{lcc}
\hline \multicolumn{1}{c}{ Subfeature } & Feasible & Not Feasible \\
\hline Wind (knot) & Calm OR $<10$ & $>=10$ \\
Cloud (octave) & Clear OR $<5$ & Cumulonimbus OR low OR $>=5$ \\
Rain $(\mathrm{mm})$ & $<400$ & $>=400$ \\
Air Temperature $\left({ }^{\circ} \mathrm{C}\right)$ & $<35$ & $>=35$ \\
Air Pressure $(\mathrm{mb})$ & $<250$ & $>=250$ \\
visibility $(\mathrm{km})$ & $>=5$ OR $\sim$ hazy & $<5$ OR hazy \\
\hline
\end{tabular}

Table 4 Subfeature of the Field State Feasibility.

\begin{tabular}{lcc}
\hline \multicolumn{1}{c}{ Subfeature } & Feasible & Not Feasible \\
\hline Transportation link & Detected & Not detected \\
Forest & Open & Closed \\
Seashore & Mid wave OR slope slightly & Steep OR muddy OR \\
& $<2,000$ & sheer OR big wave \\
Mountain & $>=2,000$ \\
\hline
\end{tabular}

Table 5 Subfeature of the Enemy Forces State.

\begin{tabular}{lcc}
\hline \multirow{2}{*}{ Subfeature } & \multicolumn{2}{c}{ Enemy } \\
\cline { 2 - 3 } & Army & Navy \\
\hline Engaged & Detected or Not Detected \\
Reinforcing & Detected or Not Detected \\
\hline
\end{tabular}

Table 6 Subfeature of the Enemy Composition State.

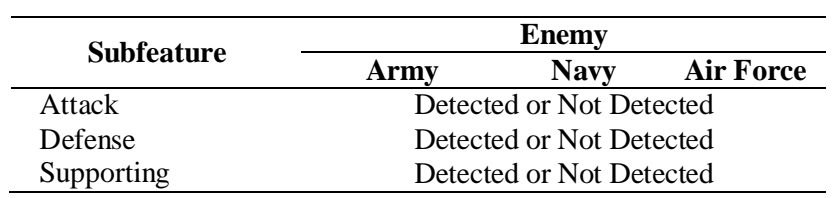

The weather, field, and enemy data are presented in Tables 7-14. The results of the information fusion done at Level 0 and Level 1 are presented in Figure 5 for primary feature Weather state $(\mathrm{cu})$, Figure 6 for primary feature Field state $(m e)$, and Figure 7 for primary feature Enemy state $(m u)$ Information fusion at Level 2 combines the results from information fusion at Level 1 to become one integrated picture as shown in Figures 8 and 9.

\subsection{Weather State Data [6] and Its Information Fusion Products}

In Figure 6, probability of weather state at each operation area is indicated by the color level of the graphic. The lighter color represents better joint declaration probability than the darker one. From information contained in this graphic, it can be inferred that the best weather state probability for executing the MO is weather state in Dry Season. 
Table 7 Weather State at DA for Level 0 Information Fusion.

\begin{tabular}{lcccc}
\hline \multirow{2}{*}{ Subfeature } & \multicolumn{4}{c}{ Season } \\
\cline { 2 - 5 } & Rainy & Inter & Dry & Average \\
\hline Wind (knot) & $5-7$ & 25 & $10-12$ & Calm \\
Cloud (octave) & $5-8$ & Nil & $1-2$ & Clear \\
Rain (mm) & 478 & 83 & 0 & 285 \\
Air Temperature $\left({ }^{\circ} \mathrm{C}\right)$ & 22,1 & Nil & 33,9 & 26 \\
Air Pressure $(\mathrm{mb})$ & Nil & Nil & Nil & Nil \\
Visibility $(\mathrm{km})$ & 1 & Nil & 10 & 10 \\
\hline
\end{tabular}

Table 8 Weather State at TR for Level 0 Information Fusion.

\begin{tabular}{lcccc}
\hline \multirow{2}{*}{ Subvariable } & \multicolumn{4}{c}{ Season } \\
\cline { 2 - 5 } & Rainy & Inter & Dry & Average \\
\hline Wind (knot) & $5-7$ & 25 & $10-12$ & Calm \\
Cloud (octave) & $5-8$ & Nil & $1-2$ & Clear \\
Rain (mm) & 478 & 83 & 0 & 285 \\
Air Temperature $\left({ }^{\circ} \mathrm{C}\right)$ & 22,1 & Nil & 33,9 & 26 \\
Air Pressure $(\mathrm{mb})$ & Nil & Nil & Nil & Nil \\
Visibility $(\mathrm{km})$ & 1 & Nil & 10 & 10 \\
\hline
\end{tabular}

Table 9 Weather State at $\mathrm{T}$ for Level 0 Information Fusion.

\begin{tabular}{lcccc}
\hline \multirow{2}{*}{ Subfeature } & \multicolumn{4}{c}{ Season } \\
\cline { 2 - 5 } & Rainy & Inter & Dry & Average \\
\hline Wind (knot) & Nil & Nil & Nil & Nil \\
Cloud (octave) & Low & Nil & Nil & Nil \\
Rain $(m m)$ & 500 & Nil & 0 & Nil \\
Air Temperature $\left({ }^{\circ} \mathrm{C}\right)$ & 20 & Nil & 35 & Nil \\
Air Pressure $(\mathrm{mb})$ & Nil & Nil & Nil & Nil \\
Visibility $(\mathrm{km})$ & 1 & Nil & Nil & Nil \\
\hline
\end{tabular}

MOAzeas vs Season Feasib:lity Prcbabi.ities

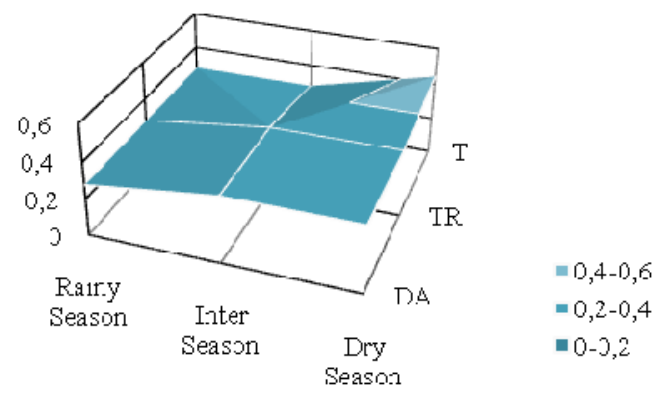

Figure 6 The information fusion product at Level 1 which fuses the joint declaration of the weather state at DA, TR, and T resulted from Level 0. 


\subsection{Field State Data [6] and Its Information Fusion Products}

Table 10 Field State at DA for Level 0 Information Fusion

\begin{tabular}{lcccc}
\hline \multirow{2}{*}{ Subfeature } & \multicolumn{4}{c}{ Field } \\
\cline { 2 - 5 } & Ground & Sea & Air & Average \\
\hline Transportation link & Detected & Detected & Detected & Nil \\
Forest & Open & Nil & Nil & Nil \\
Seashore & Nil & Nil & Nil & Nil \\
Mountain & Not Detected & Nil & Nil & Nil \\
\hline
\end{tabular}

Table 11 Field State at TR for Level 0 Information Fusion.

\begin{tabular}{lcccc}
\hline \multirow{2}{*}{ Subfeature } & \multicolumn{4}{c}{ Field } \\
\cline { 2 - 5 } & Ground & Sea & Air & Average \\
\hline Transportation link & Detected & Detected & Detected & Nil \\
Forest & Open & Nil & Nil & Nil \\
Seashore & Nil & Nil & Nil & Nil \\
Mountain & Not Detected & Nil & Nil & Nil \\
\hline
\end{tabular}

Table 12 Field State at $\mathrm{T}$ for Level 0 Information Fusion.

\begin{tabular}{lcccc}
\hline \multirow{2}{*}{ Subfeature } & \multicolumn{4}{c}{ Field } \\
\cline { 2 - 5 } & Ground & Sea & Air & Average \\
\hline Transportation link & Detected & Detected & Detected & Nil \\
Forest & Close & Nil & Nil & Nil \\
Seashore & Big Wave & Nil & Nil & Big Wave \\
Mountain & Detected & Nil & Nil & Nil \\
\hline
\end{tabular}

N-U Areas rs zield Feasibility Probabilities

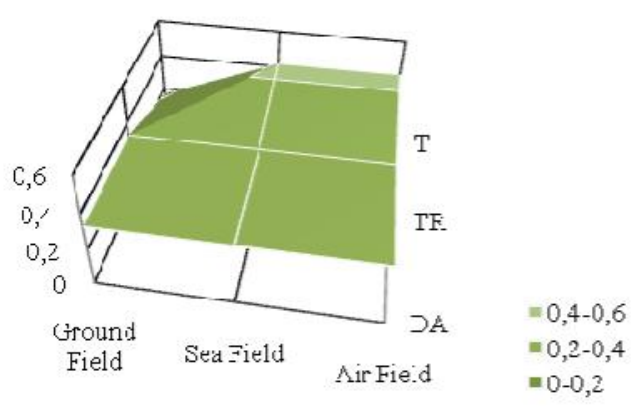

Figure 7 The information fusion product at Level 1 which fuses the joint declaration of the field state at DA, TR, and T resulted from Level 0.

From the fused information presented in Figure 7, it can be inferred that the best field state probability, which enables execution of the MO, is field state of Sea Field and Air Field. 


\subsection{Enemy State Data [6] and Its Information Fusion Products}

Table 13 Enemy Forces State for Level 0 Information Fusion.

\begin{tabular}{lccc}
\hline \multirow{2}{*}{ Subfeature } & \multicolumn{3}{c}{ Enemy } \\
\cline { 2 - 4 } & Army & Navy & Air Force \\
\hline Engaged & Detected & Nil & Detected \\
Reinforcing & Nil & Detected & Nil \\
\hline
\end{tabular}

Table 14 Enemy Composition State for Level 0 Information Fusion.

\begin{tabular}{lccc}
\hline \multirow{2}{*}{ Subfeature } & \multicolumn{3}{c}{ Enemy } \\
\cline { 2 - 3 } & Army & Navy & Air Force \\
\hline Attack & Detected & Detected & Detected \\
Defense & Detected & Detected & Detected \\
Supporting & Nil & Detected & Detected \\
\hline
\end{tabular}

From Figure 8 it can be inferred that the greatest enemy Forces probability is the Navy with the greatest enemy Composition is joint forces of the Navy and the Air Force.

Er.erny D:mension 7s Enemy Existence Probabilities

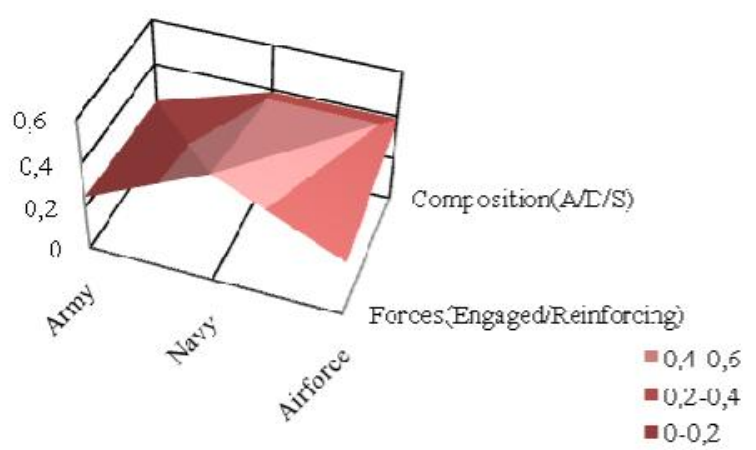

Figure 8 The information fusion product at Level 1 which fuses the joint declaration of enemy forces and composition states resulted from Level 0.

\subsection{Weather, Field, and Enemy State Information Fusion [9]}

At Level 2, the system fuses weather, field, and enemy joint declaration resulted from Level 1 to become one integrated joint declaration of weatherfield-enemy as depicted in Figures 9 and 10. The joint declaration of the weather-field-enemy state probability is indicated by color level of the graphic and the value is pointed out by its elevation from graphic base. From these integrated pictures, the IA will produce an inference as follow: "The execution of the MO will have better probability to be accomplished if 
it is done in Dry Season, by means of Air and or Sea Field while anticipating the enemy's Navy and Air Force Engaged/Reinforcing join forces with Composition of Attack, Defense, and Supporting troops".

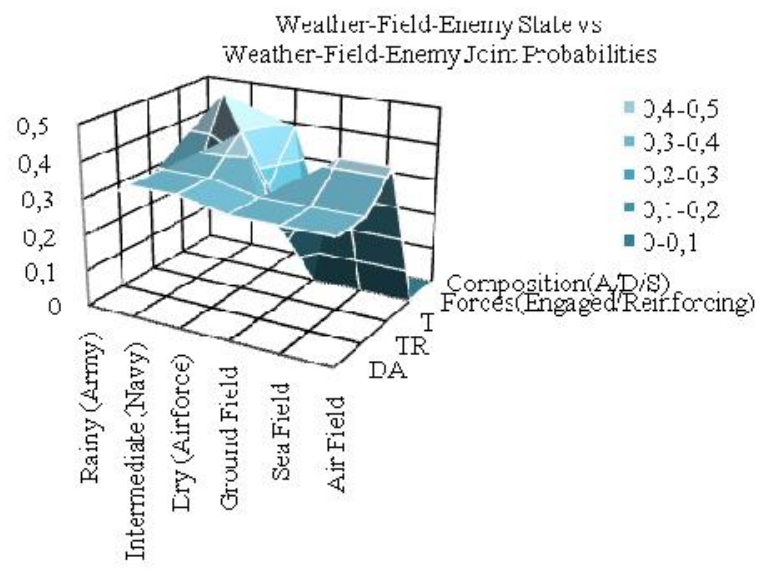

Figure 9 The information fusion product at Level 2 that fuses the joint declaration of weather, field, and enemy resulted from Level 1.

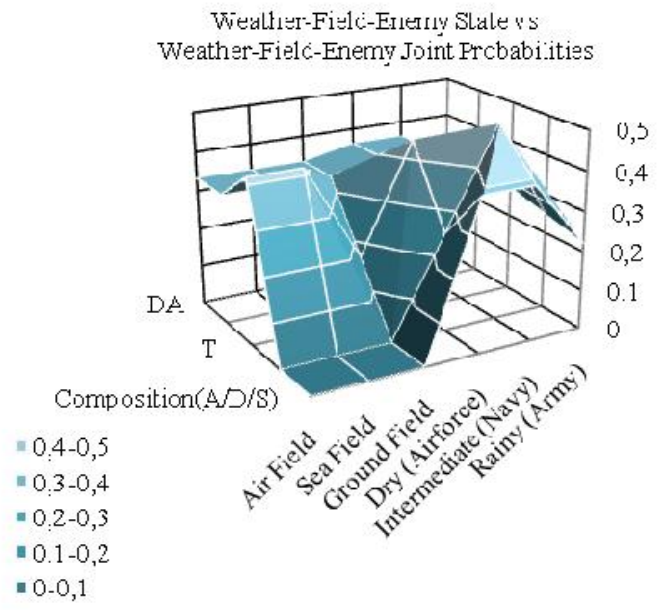

Figure 10 The information fusion product at Level 2 that fuses the joint declaration of weather, field, and enemy resulted from Level 1. This view is required in order to observe the unseen information that is not clearly shown in Figure 9. 


\section{$5 \quad$ Concluding Remarks}

The longest phase in OODA decision cycle is the Observe phase [1] where the gathered intelligence data/information is analyzed from five perspectives. This phase becomes longer when the data/information analyzing is done in conventional manners and without any information processing method at all as now still done in Indonesian military community. So, the research results presented in this paper show that MAIFS-DMS is very helpful in supporting decision making in an MO planning by automating the data/information process from information multi-source to the commandant's post command in a quick manner. As the consequence, it reduces the Observe phase and reduces the whole OODA cycle. The shorter the OODA cycle the quicker the commandant makes a strategic decision. On the other hand, the more comprehensive the information presented, the more correct and accurate the decision that is made by the commandant. The accurate and correct decision can prevent his commanding forces from doing any incorrect actions that can cause loss in personnel and or materials.

Our research results by using a military training intelligence database show that the Maximum Score of the Total Sum of Joint Probabilities (MSJP) inference method has been proven as feasible method for information fusion that produces an inference regarding to the MO dynamics. We compare the results with the version done by the Student Officers when conducting War Game [6]. Most of the related works in information fusion is aimed for targets tracking, identification, and detection [3,4,7,12-14] and no single work that mentions the work like the one presented in this paper. The work done by [16] uses different approach but it only applies to intelligence data and does not utilize multiagent approach.

With these research promising results, our future work will be to develop and apply MSJP method combined with the multiagent system for more complex systems applications.

\section{$6 \quad$ Nomenclature}

Only one operator is used for information fusion process.

$\oplus \quad=\quad$ information fusion operator

\section{Acknowledgement}

The first author would like to present great gratitude to former Chief of Staff of the Indonesian Air Force, Air Chief Marshal (ret) Herman Prayitno, Chief of Staff of the Indonesian Air Force, Air Chief Marshal Subandrio, 
Governor of Akademi Angkatan Udara, and their staffs for supporting his Magister Teknik study in School of Electrical Engineering and Informatics, Institut Teknologi Bandung, Bandung, Indonesia.

\section{References}

[1] Joint Doctrine for Command and Control Warfare (C2W), Joint Publication 3-13.1, US Department of Defense, 7 February 1996.

[2] Steinberg, A.N. et.al, Revisions to the JDL Data Fusion Model, Sensor Fusion: Architectures, Algorithms, and Applications, Proceedings of the SPIE, Vol. 3719, 1999.

[3] Brooks, R.R. \& Iyengar, S.S., Multi-Sensor Data Fusion: Fundamentals and Applications with Software, Prentice-Hall, 1998.

[4] Hall, D.L., Mathematical Techniques in Multisensor Data Fusion, Artech House, 1992.

[5] Ahmad, Adang S. \& Sumari, Arwin D.W., Multi-Agent Information Inferencing Fusion in Integrated Information System, to be published by ITB Publisher, 2008.

[6] Command Post Rehearsal of the Class $73^{\text {rd }}$ Student Officer (Olah Yudha SEKKAU LXIII), School of Unity of Command of the Indonesian Air Force, 2003.

[7] Hall, D.L. \& Llinas, J., Handbook of Multisensor Data Fusion, CRC Press LLC, 2001.

[8] Bedworth, M. \& O'Brien, J., The Omnibus Model: A New Model of Data Fusion?, IEEE Aerospace and Electronic Systems (AES) Magazine, 15(4), April 2000.

[9] Sumari, Arwin D.W., Design and Implementation of MultiAgent-based Information Fusion System for Supporting Decision Making in Air Operation Planning, Magister Teknik Thesis, Institut Teknologi Bandung, 2008. (in Indonesian).

[10] Bedworth, M. \& Heading, A.J.R., The Importance of Models in Bayesian Data Fusion, Defence Research Agency, England, http://citeseerx.ist.psu.edu/viewdoc/summary?doi=10.1.1.48.2123, May 2007).

[11] Brynielson, J. \& Arnborg, S., Bayesian Games for Threat Prediction and Situation Analysis, Department of Numerical Analysis and Computer Science, Royal Institute of Technology, http://www.nada.kth.se/ joel/ IF04-1125.ps, (3 April 2007).

[12] Cremer, F. et.al., Detection of Anti-Personnel Land-mines using SensorFusion Techniques, Proceeding of EuroFusion99, T. Windeatt \& J. O’Brien, pp. 159-166, 1999.

[13] Koks, D. \& Challa, S., An Introduction to Bayesian and Dempster-Shafer Data Fusion, DSTO-TR-1436, Electronic Warfare and Radar Division, 
Systems Sciences Laboratory, Defence Science \& Technology, http://dspace.dsto.defence.gov.au/dspace/bitstream/1947/4316/1/DSTOTR-1436.pdf, (5 June 2007).

[14] Lauberts, A. et.al, Ground Target Classification Using Combined Radar and IR with Situated Data, Swedish Defence Research Agency, http://www.fusion2004.foi.se/papers/IF04-1088.pdf, (6 July 2007).

[15] Luo, R.C. et.al, Multisensor Fusion and Integration: Approaches, Applications, and Future Research Directions, IEEE Sensors Journal, 2(2), 107-119, 2002.

[16] McNaught, K.R. et.al., Investigating the Use of Bayesian Networks to Provide Decision Support to Military Intelligence Analysts, Engineering Systems Department, Cranfield University, http://www.comp.glam.ac.uk/ ASMTA2005/Proc/pdf/is-04.pdf, (15 July 2007).

[17] Shi, X. \& Manduchi, R., A Study on Bayes Feature Fusion for Image Classification, Department of Computer Engineering, University of California, Santa Cruz, http://www.cse.lehigh.edu/ rjm2/SACV/papers/ shi-manduchi.pdf, (25 September 2007).

[18] Smarandache, F. \& Dezert, J., Advances and Applications of DSmT for Information Fusion, American Research Press, 2004.

[19] Bennett, P.N. et.al., Probabilistic Combination of Text Classifiers Using Reliability Indicators: Models and Results, Computer Science Dept., Carnegie Mellon University, http://research.microsoft.com/ sdumais/ sigir2002-combo.pdf, (14 June 2007).

[20] Chen, Y. et.al, Two-Phase Decision Fusion Based on User Preference, Integrated Media Systems Center University of Southern California, http://infolab.usc.edu/DocsDemos/hiccomputers2004.pdf, (13 November 2008).

[21] McDonald, K. \& Smeaton, A.F., A Comparison of Score, Rank and Probability-based Fusion Methods for Video Shot Retrieval, Centre for Digital Video Processing, Dublin City University, http://doras.dcu.ie/ 269/01/lncs_3568.pdf, (15 July 2007).

[22] Shaw, J.A. \& Fox, E.A., Combination of Multiple Searches, Department of Computer Science, Virginia Tech, Blacksburg, http://trec.nist.gov/ pubs/trec3/papers/vt.ps.gz, (27 November 2007).

[23] Wooldridge, M., An Introduction to Multiagent Systems, John Wiley \& Sons, 2002.

[24] Russel, S.J. \& Norvig, P., Artificial Intelligence: A Modern Approach $2^{\text {nd }}$ Edtion, Prentice-Hall, 2002.

[25] Bradshaw, J.M. (Editor), Software Agents, AAAI Press/The Press, 1994.

[26] Dugat, J., SMAS - A MultiAgent System for Efficient Strategy and Tactics in Wargames, Master of Science Thesis, Staffordshire University, UK, 2004. 
[27] Faltings, B., Intelligent Agents: Software Technology for the New Millenium, Informatique Magazine, No. 1, pp. 2-5., 2000.

[28] Franklin, S., \& Graesser, A., Is it an Agent, or Just a Program?: A Taxonomy for Autonomous Agents, http://www.intelligence.tuc.gr/ $\sim$ robots/ARCHIVE/ 2006/readings/IsItAnAgentOrJustAProgram.pdf. (20 March 2008).

[29] Nwana, H.S., Software Agents: An Overview, Knowledge Engineering Review,11(3), 205-244, 1996.

[30] Rudowsky, I., Intelligent Agents, Brooklyn College, http://userhome. brooklyn.cuny.edu/irudowsky/Papers/IntelligentAgentsTutorial.pdf, (3 December 2007).

[31] Gorodetsky, V. et.al, Multi-agent Data Fusion Systems: Design and Implementation Issues, Intelligent System Laboratory, St. Petersburg Institute for Informatics and Automation, http://space.iias.spb.su/ai/ publications/2002-GKS-MADFS.pdf, (22 August 2007).

[32] Sycara, K.P., Multiagent Systems, AI Magazine, American Association for Artificial Intelligence (AAAI), pp. 78-92, 1998.

[33] Guessoum, Z., Adaptive Agents and Multiagent Systems, IEEE DS Online Exclusive Content, http://dsonline.computer.org/portal/site/dsonline, (2 Januari 2008).

[34] Sumari, Arwin D.W., Design and Implementation of Intelligent Information Retrieval System based on Adaptive Resonance Theory 1 Artificial Neural Network, Sarjana Teknik Final Project, Institut Teknologi Bandung, 1996. (in Indonesian). 